\title{
Human Aspects of IT-Supported Performance Measurement System
}

\author{
Sai S. Nudurupati and Umit S. Bititci \\ University of Strathclyde, Centre for Strategic Manufacturing, 75 Montrose Street, Glasgow \\ GI IXJ, United Kingdom. \\ Email: sai.nudurupati@strath.ac.uk
}

\begin{abstract}
In the field of performance measurement, a lot of literature is emerging, which largely focuses on designing performance measurement systems, with few studies on issues in implementation and use of performance measurement systems. The objective of this paper is to study the people related issues surrounding the implementation and use of IT-supported performance measurement system (IT-PMS). Action research was chosen as the main methodology and IT-PMS was implemented in three companies. The study has identified different human factors, such as senior management commitment, drive, overcoming resistance, training, etc., that would enable IT-PMS implementation and bring positive impact on management behaviour and business results.
\end{abstract}

Key words: Performance measurement, Human factors, IT, Management and business implications

\section{INTRODUCTION}

The performance measurement revolution started in the late 1970s and early 1980 s with the dissatisfaction of traditional backward looking accounting systems. Since then, there has been constant development in this field. Most of the focus has been on designing performance measurement systems, with few studies illustrating the issues in implementing and using performance measurement systems (BOURNE 2000; NUDURUPATI, BITITCI 2003a; KENNERLY 2003). According to BITITCI (2002) and HOLLOWAY (2001), there is little solid research evidence that illustrates 
the impact of performance measurement systems. The objective of this paper is to identify the human aspects (factors) of an IT-supported Performance Measurement System (IT-PMS) and understand how it impacts management behaviour and business results.

\section{BACKGROUND}

There has been constant development in the field of performance measurement. There are a number of frameworks and models developed for designing performance measures from strategy. However, while implementing these performance measures, usually indicators are poorly defined (SCHNEIDERMAN 1999), which can lead to misunderstanding. Hence, the measures and indicators should be clearly defined (BOURNE et al. 1998, NEELY et al. 1996), understood and communicated. According to BOURNE et al. (2000), MARR et al. (2002) and NUDURUPATI et al. (2000), for implementing each measure, the following tasks are required:

- Data Creation: The policies, procedures and systems required to create the data required.

- Data Collection: The collection of data at regular intervals.

- Data Analysis: The conversion of the collected data into useful information, in the form of trend charts, comparison charts, summary reports, statistical analysis, etc.

- Information Distribution: The communication of this information to the right people in the business for assisting decision-making.

According to BITITCI et al. (2000), BOURNE et al. (2000), HUDSON et al. (2001), NEELY (1999), BIERBUSSE et al. (1998), IT plays a major role in performance measurement implementation. However to demonstrate that IT-supported performance measurement system (IT-PMS) will have a positive or negative impact on management and business, it is necessary to design, implement and monitor IT-PMS in organisations. For doing this, in addition to performance measurement, it is also necessary to review the literature on understanding and managing change in the organisations.

According to LEWIN's $(1947 ; 1951)$ theory of force field-analysis, there are two sets of forces in operation within a social system - one driving the force to operate for a change and the other trying to increase the resisting forces. In order to maintain a successful change, the implementation team either should increase the driving forces or decrease the resisting forces. BURNS and STALKER's (1961) approach highlights the importance of an organisation's ability to adapt to the turbulent environment and includes two contrasting management systems: mechanistic system and organic system. 
GALBRAITH (1973) identified that within an organisation, research and development departments have organic systems and production departments have mechanistic systems.

In the late 1980's DUNPHY and STACE (1990) proposed a two dimensional framework based on the scale of change, such as fine tuning, incremental adjustment, modular transformation or corporate transformation, as well as the style of leadership, such as collaborative, consultative, directive or coercive. Two independent researches by PETTIGREW (1990) and CHILD et al. (1987) identified that a contextualist approach is required, which includes three elements:

- the content for the change programme,

- the process of change programme, and

- the context in which changes occur.

ORLIKOWSKI (1996) and MINTZBERG (1987) criticised most of the change approaches for neglecting a distinction between deliberate and emergent change. They argue that emergent change can only be realised in "action".

However, the success of IT-supported performance measurement implementations lie in availability of performance information, as well as how people use and behave with the available performance information (PRAHALAD et al. 2002; ORLIKOWSKI 2000; MARCHAND et al. 2000; DAVENPORT 1997; ECCLES 1991). MEEKINGS (1995) argues that making people use measurements properly not only delivers performance improvement but also becomes a vehicle for a cultural change, which helps liberating the power of the organisation.

Hence, when a performance measurement system is implemented in an organisation, there are several factors (both technical and human factors) that will affect its design, implementation and use. Some of these factors include:

- lack of time and effort required (BOURNE et al 2000; HUDSON et al. 2001),

- lack of IT support (BITITCI et al. 2002; BOURNE et al. 2000; HUDSON et al. 2001),

- lack of accuracy and timeliness of information (HUDSON et al. 2001; NEELY 1999),

- lack of senior management drive and commitment (BITITCI et al. 2002; BOURNE et al. 2000; HUDSON et al. 2001), and

- resistance (BITITCI et al. 2002; BOURNE et al. 2000). 


\section{METHODOLOGY}

However, human factors (extraneous variables) can only be realised in action and cannot be anticipated or planned. Hence, the researcher should be part of the organisation and understand how and why their actions with ITPMS in the organisation will bring about change in working practices as well as behaviours of people, groups and organisation (COGHLAN et al. 2001). In order to achieve this and identify the human factors, action research was chosen as the main methodology.

IT-PMS was implemented at three companies, ADL (bottling company), HSL (mineral water company) and SLC (label company). Throughout the research, the authors played $a$ dual role as facilitators and/or personal observers. At ADL and SLC the authors acted as facilitators and implemented IT-PMS. However, at HSL an internal team within the company had implemented IT-PMS, whereas the authors acted as participant observers. A number of interviews were also held with the senior management and middle management teams, which led the authors to understand the before and after scenarios and validate the results with their personal observations at these three companies.

\section{ACTION CASES: IMPLEMENTING AND USING IT-PMS}

Prior to implementing IT-PMS in all three companies, data was distributed and scattered throughout the organisation. There were many difficulties and obstacles for implementing and using performance measurement. Since data was available from different sources, a significant amount of time and effort was required to collect, analyse and communicate the information to different people. Together with out of date business priorities and performance measurement (often lagging indicators), this raised questions on accuracy and timeliness of information, as shown in Figure 1. This made the management loose their confidence in the information available. Together with fear of exposure as people were pulled into light, this had initiated resistance from people in implementing performance measurement.

As a result of these obstacles and difficulties for successful implementation and use of performance measurement system, the management at these three companies decided to implement IT-PMS. In all of the three companies, the data collection, analysis and communication were automated to the maximum extent possible. Information (password protected) was made available and accessible through the intranet in near real-time. 


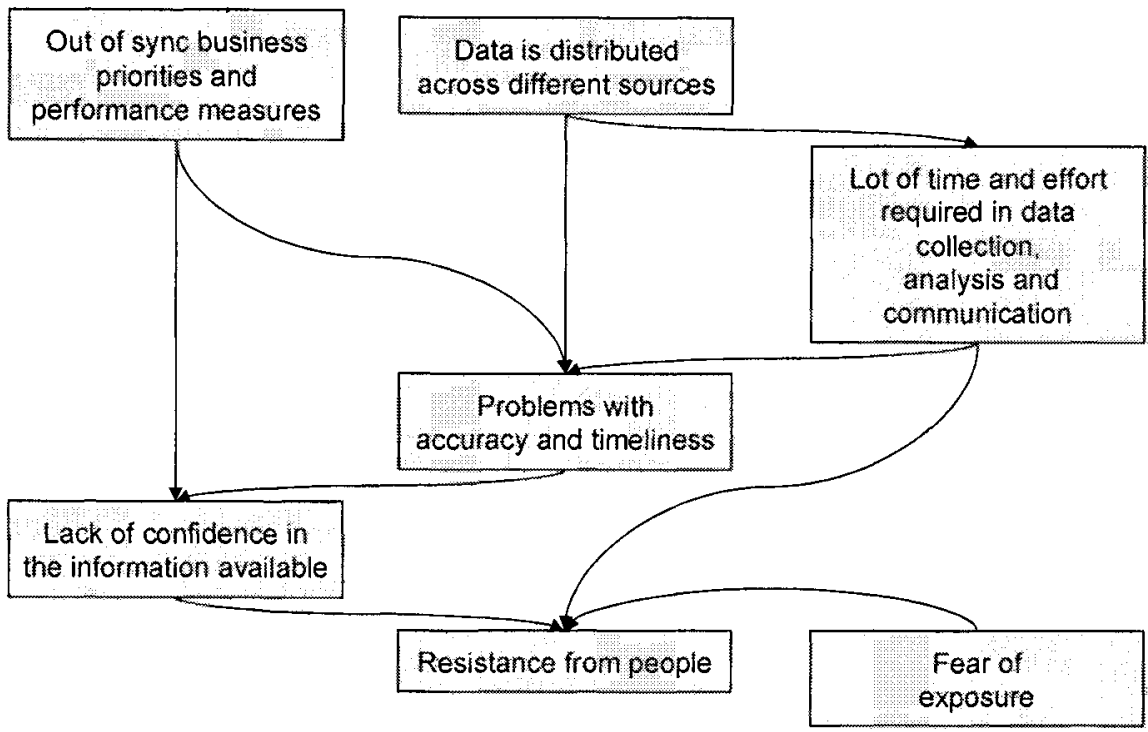

Figure 1. Factors obstructing the IT-PMS implementation (Source: NUDURUPATI, BITITCI 2003b, p. 63)

\subsection{Action Case: ADL}

At ADL, IT-PMS was only implemented for operational activities of the companies, using in-house technology together with a Statistical Process Control (SPC) charting tool (a software tool used to produce control charts, attribute charts, Pareto analysis, etc.). However, there were significant improvements on quickly identifying the weaknesses of business, facilitating continuous improvement of production lines, as well as facilitating proactive decision-making. Also, it made only little improvement on encouraging positive behaviour of the people. The significant improvements were due to the following reasons:

- The senior management were committed to the project.

- Management gained confidence in performance information generated by the system in near-real-time.

- The performance results were communicated to everyone in the organisation, especially all team leaders and people on the shop floor.

- People were encouraged for identifying trends and, hence, identify root causes of the problem using continuous improvement techniques. 
However, the reasons why the system did not make significant impact on someone are:

- The people on the shop floor did not start using the system because they did not have the facilities (i.e. computers, displays, etc.) to display information on the production lines.

- Some managers lacked vision in terms of what they wanted to gain from this implementation.

\subsection{Action Case: HSL}

At HSL, IT-PMS was implemented for the whole organisation, with inhouse technology using Cognos reporting tool (NUDURUPATI et al. 2000). Immediately after implementing IT-PMS, there were no improvements as the project was no longer a priority and more important projects were launched. Hence, the IT-PMS was not used. However, the implementation of new production facilities led to productivity problems, requiring senior management's attention to productivity-related performance issues and measures. This led to a senior management drive for proper use of the IT-PMS, resulting in significant improvements by quickly identifying and focusing on the weaknesses of the business, facilitating continuous improvement, facilitating pro-active decision-making and encouraging positive behaviour. The reasons behind this improvement were:

- Senior management was committed to the system and its use. They used it every day to ask questions relating to the performance.

- The management team gained confidence in performance information generated by the system because the data was accurate and timely.

- The performance results were communicated to everyone in the organisation, especially all team leaders and people on the shop floor.

- Senior management was taking the drive in making people use the system as their routine everyday business, making decisions based on facts.

- Senior management encouraged a cross-functional, flexible, team-based working culture.

- Senior management encouraged people to use the system through nonthreatening management style and communicated the potential benefits of IT-PMS.

- People were encouraged to identify performance trends and root causes of the problem using continuous improvement techniques. 


\subsection{Action Case: SLC}

At SLC, IT-PMS was only implemented for the operational activities of the company, using in-house technology together with an SPC charting tool. However, there were no improvements in this company because of the following reasons:

- The IT-PMS was implemented only for the operational activities of the company.

- There were technical limitations in the data collected on the shop floor (the automated data capturing system cannot be changed).

- Senior management did not develop confidence in the system due to the limitations in the data capturing and, hence, did not drive the companywide use of the system.

- Consequently the performance results were not communicated to in the organisation, especially team leaders and people on the shop floor.

\section{HUMAN FACTORS OF IT-PMS AND THEIR IMPACT}

The human factors identified while implementing and using IT-PMS at these three action case companies are tabulated in Table 1. These factors are also classified, based on the level of significance of their existence in each company.

Table 1. Summary of human factors identified at action cases

\begin{tabular}{|l|c|c|c|}
\hline \multicolumn{1}{|c|}{ Human Factor } & ADL & HSL & SLC \\
\hline 1. Senior management commitment & Significant & Significant & Moderate \\
\hline 2. Drive from senior management & Significant & Significant & None \\
\hline 3. Communicate the benefits to people & Significant & Significant & Moderate \\
\hline 4. Usage of the IT-PMS & Significant & Significant & None \\
\hline 5. Proactive decision-making & Significant & Significant & None \\
\hline 6. Overcome resistance from people & Moderate & Significant & None \\
\hline
\end{tabular}

From these three action cases it was observed that these human factors of ITPMS would impact management behaviour and business results, as shown in the Table 2. The people and technical factors identified from the individual cases and cross-case analysis would act as enablers between IT-PMS imple- 
mentation and the management and business implications, as demonstrated in Figure 2.

Table 2. Summary of management and business implications at action cases

\begin{tabular}{|l|l|l|l|}
\hline \multicolumn{1}{|c|}{ Management and Business Implication } & ADL & HSL & SLC \\
\hline 1. Identifying weaknesses of the business & Significant & Significant & None \\
\hline 2. Facilitating continuous improvement & Significant & Significant & None \\
\hline 3. Facilitating pro-active decision-making & Significant & Significant & None \\
\hline 4. Improving positive behaviour of the people & Moderate & Significant & None \\
\hline
\end{tabular}

IT-PMS implementation should ensure that the positive impact on the following technical factors were realized:

- Up-to-date information in real-time is presented

- Data accuracy is ensured

- Information is communicated

If the information is available up-to-date in real-time and is ensured for accuracy, it would create confidence in people. These factors would lead to senior management commitment, and hence they would take the drive into their hands and ensure the following people factors are in place:

- Provide necessary training for people to overcome resistance and make them use IT-PMS

- Communicate perceived benefits to make people realize the importance of IT-PMS

- Overcome resistance from people

- Initiate team culture

- Empower people in making decisions based on the information available from IT-PMS

All these factors lead people to use IT-PMS as a routine part of the business in decision-making. These people factors would result in management and business implications. As the management is confident about the information and use it as a routine part of business, it would lead to a proactive management style, which would also lead them in identifying weak areas of the business. This together with team culture would result in continuous improvement. As the business experiences most of these people factors it would build positive behaviour of the people. 


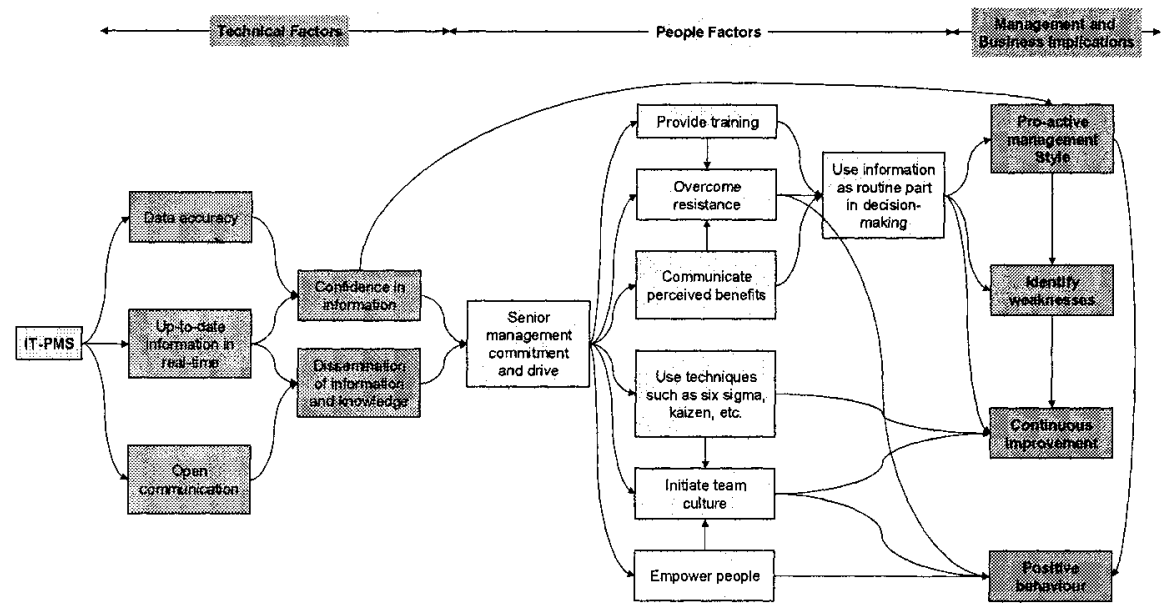

Figure 2. Technical and human factors affecting management and business

\section{DISCUSSION}

As demonstrated in Tables 1 and 2, at ADL and HSL senior management commitment and active participation (i.e. drive) played a significant role to make the implementation a success. In both these cases the initiative was taken to ensure that the performance information presented was accurate and consistent. Since the information available was accurate, reliable and consistent, management used IT-PMS as part of their daily routine business, identifying trends and making pro-active decisions. With an open and nonthreatened management style, they insisted that everyone used the system.

Initially, in both these companies there was some resistance at lower levels (including some management levels) to using IT-PMS. However, to overcome resistance in these companies, the senior management explained and communicated the implications and benefits of using IT-PMS in their management briefings. They provided necessary training on IT-PMS for people who required it. They also insisted that all performance related discussion should be focused around the information presented on the system and not on information available elsewhere. This made the management at lower levels realise the benefits of the system and so they started using ITPMS in their decision-making.

Most of the managers at ADL are bureaucratic and based their decisions on experience rather than on factual information. Prior to IT-PMS, some of the managers were unfocused and not clear about their objectives. However, 
the implementation of IT-PMS enabled the managers to augment their experience with accurate and timely performance information based on facts.

Even though the management style at HSL was bureaucratic, when ITPMS was implemented, the company soon launched another project to change the management structure to a more flat structure. This enabled the self-managed autonomous teams to use the performance information available from IT-PMS in decision-making and drive continuous improvement.

Even though the senior management at SLC were initially committed to the project, they lost confidence in the accuracy of information generated by IT-PMS due to the limitations of data capturing. Hence, they were not committed to the rest of the project. As a result they did not drive the people into using the system. Thus people at lower levels did not bother using the ITPMS. Therefore, in contrast to ADL and HSL, there was no change in the management style at SLC, as the management did not use IT-PMS in decision-making. The IT-PMS was suspended after six months of its implementation.

\section{CONCLUSION}

The action research, through these three cases, demonstrated that appropriately designed IT-PMS (by selecting the right set of performance measures), appropriately implemented in a company, would ensure the following technical factors:

- data accuracy,

- up-to-date information presented in real-time, and

- open communication.

Appropriately used (with drive and commitment from senior management) IT-PMS would ensure the following people factors:

- communicating perceived benefits of IT-PMS,

- providing training where necessary,

- overcoming resistance (the above two factors help for this factor),

- making people use IT-PMS in decision-making for the business,

- initiating team culture, and

- empowering people.

These technical and people factors of IT-PMS, in turn, would impact the management behavior and business results as follows:

- increases pro-active management style,

- increases positive behaviour such as focusing on facts, communication, empowerment and teamwork, 
- identifies weak areas of the business, and

- promotes continuous improvement.

\section{REFERENCES}

BIERBUSSE, P.; SIESFELD, T.:

Measures that Matter.

In: Journal of Strategic Performance Measurement,

Boston, MA, 1(1998)2, pp. 6-11.

BITITCI, U. S; TURNER, T.; BEGEMANN, C.:

Dynamics of Performance Measurement Systems.

In: International Journal of Operations and Production Management,

Bradford, 20(2000)6, pp. 692-704.

BITITCI, U. S.; NUDURUPATI, S. S.; TURNER, T. J.; CREIGHTON, S.:

Web enabled Performance Measurement System: Management Implications.

In: International Journal of Operations and Production Management,

Bradford, 22(2002)11, pp. 1273-1287.

BOURNE, M.; WILCOX, M.:

Translating strategy into action.

In: Manufacturing Engineer,

London 77(1998)3, pp. 109-112.

BOURNE, M.; NEELY, A.:

Why performance measurement interventions succeed and fail.

In: Proceedings of the 2nd International Conference on Performance Measurement.

Ed: NEELY, A.

Cranfield: Centre for Business Performance, Cranfield University, 2000, pp. 165-173.

BURNS, T.; STALKER, R.:

The Management of Innovation.

London: Tavistock Publications, 1961.

CHILD, T,; SMITH, C.:

The Context and Process of Organisational Transformation.

In: Journal of Management Studies,

Oxford, 24(1987)6, pp. 565-593.

COGHLAN, D; BRANNICK, T.:

Doing Action Research in Your Own Organisation.

London: Sage Publications, 2001.

DAVENPORT, T. H.:

Information Ecology.

Oxford: Oxford University Press, 1997.

DUNPHY, D.; STACE, D.:

Under New Management: Australian Organizations in Transition.

Sydney: McGraw-Hill, 1990. 
ECCLES, R. G.:

The Performance Measurement Manifesto.

In: Harvard Business Review,

Boston, MA, 69(1991)1, pp. 131-137.

GALBRAITH, J. R.:

Designing Complex Organizations.

Reading, MA: Addison-Wesley Publishing, 1973.

HOLLOWAY, J.:

Investigating the impact of performance measurement.

In: International Journal of Business Performance Management,

Leicester, 3(2001)2/3/4, pp. 167-180.

HUDSON M.; SMART A.; BOURNE M.:

Theory and practice in SME performance measurement systems

In: International Journal of Operations and Production Management,

Bradford, 21(2001)8, pp. 1096-1115.

KENNERLY, M.; NEELY, A.:

Measuring performance in changing business environment.

In: International Journal of Operations and Production Management,

Bradford, 23(2003)2, pp. 213-229.

LEWIN, K.:

Frontiers in Group Dynamics.

In: Human Relations, London, 1(1947)1, pp. 5-41.

LEWIN, K.:

Field Theory in Social Science.

London: Harper and Row, 1951.

MARCHAND, D.; KETTINGER, W.; ROLLINS, J.:

Company Performance and IM: the view from the top.

In: Mastering Information Management.

Eds.: MARCHAND, D.; DAVENPORT, T.; DICKSON, T.

London: Financial Times Prentice Hall, 2000, pp. 10-16.

MARR, B.; NEELY, A.:

Balanced Scorecard Software Report.

Stamford, CT: InfoEdge, Two Stamford Landing, 2002.

MEEKINGS. A.:

Unlocking the Potential of Performance Measurement: A Practical Implementation Guide.

In: Public Money \& Management,

Oxford, 7(1995)4, pp. 5-12.

MINTZBERG, $\mathrm{H}$ :

Crafting Strategy.

In: Harvard Business Review,

Boston, MA, 65(1987) July-August, pp. 66-75.

NEELY, A.; MILLS, J.; GREGORY, M.; RICHARDS, H.; PLATTS, K.; BOURNE, M.:

Getting the measure of your business.

Cambridge: University of Cambridge, Manufacturing Engineering Group, 1996.

NEELY, A.:

The performance measurement revolution: why now and what next?

In: International Journal of Operations and Production Management,

Bradford, 19(1999)2, pp. 205-228. 
NUDURUPATI, S. S.; BITITCI, U. S.:

Review of Performance Management Information Systems (PerforMIS).

Internal Report.

Strathclyde: University of Strathclyde, Centre for Strategic Manufacturing, DMEM, 2000.

NUDURUPATI, S. S.; BITITCI, U. S.:

Implementation and Impact of IT enabled Performance Measurement.

IFIP 3rd International Workshop.

Bergamo, Italy, 19-20 June 2003.

$(=2003 \mathrm{a})$

NUDURUPATI, Sai S.; BITITCI, Umit S.:

Human Aspects of IT-Supported Performance Measurement System.

In: Human Aspects in Production Management.

Eds.: ZÜLCH, Gert; STOWASSER, Sascha; JAGDEV, Harinder S.

Aachen: Shaker Verlag, 2003, pp. 60-67.

(esim - European Series in Industrial Management, Volume 5)

(=2003b)

ORLIKOWSKI, W. J.:

Improvising Organisational Transformation Over Time: A Situated Change Perspective.

In: Information Systems Research,

Linthicum, MD, 7(1996)1, pp. 63-92.

PETTIGREW, A.:

Longitudinal Field Research on Change: Theory and Practice.

In: Organization Science,

Linthicum, MD, 1(1990)3, pp. 267-292.

PRAHALAD, C. K.; KRISHNAN, M. S.:

The Dynamic Synchronisation of Strategy and Information Technology.

In: MIT Sloan Management Review,

Cambridge, MA, 2(2002)Summer, pp. 24-33.

SCHNEIDERMAN, A. M.:

Why Balanced Scorecards Fail.

In: Journal of Strategic Performance Measurement,

Boston, MA, 2(1999), pp. 6-11. 